\title{
The Propensity to Trust Others: Gender and Country Differences
}

\author{
Ayush B. Shrestha ${ }^{1}$, Richard A. Bernardi ${ }^{1} \&$ Susan M. Bosco ${ }^{1}$ \\ ${ }^{1}$ Gabelli School of Business, Roger Williams University
}

Correspondence: Richard A. Bernardi, Gabelli School of Business, Roger Williams University, Bristol, RI 02809, USA. Off: 1-401-254-3672. Fax: (401)-254-3545. E-mail: rbernardi@rwu.edu

Received: April 24, 2013

Accepted: May 13, 2013

Online Published: May 14, 2013

doi:10.5430/afr.v2n2p69

URL: http://dx.doi.org/10.5430/afr.v2n2p69

\begin{abstract}
Our research examines the level of individual trust in others, which is an important issue because it essentially determines the level of additional work that must be done by auditors to make their audit decision. This study includes the responses of 315 accounting students from Afghanistan, Australia, Nepal, and the United States. It then examines whether levels of trust vary by country. Our data indicate that students from both Australia and Nepal had significantly different levels of trust than the students from the United States (our control group). While the students from Nepal had a significantly lower level of trust than the students from the United States, the students from Australia had a significantly higher level of trust than the students from the United States. Additionally, male (female) students indicated a lower (higher) level of trust. Our finding of differences among countries in the level of individual trust has implications in the field of international auditing. While the countries of the world are working at harmonizing their accounting and auditing standards, differences in the amount of work actually done on an audit could be determined by the level of trust in a client. The sample includes Afghanistan and Nepal that are not presently included in auditing-related research.
\end{abstract}

Keywords: Auditing, Trust, Gender differences, Afghanistan, Nepal

\section{Introduction}

The impact of the ability of an auditor to trust a client has also been well documented in the research. For example, a firm's evaluation of a client's integrity (i.e., a measure of the level of trust) affected the firm's perception of a potential client (Ayers \& Kaplan, 2003; Johnstone \& Bedard, 2004) and whether to continue as the auditor of an existing client (Johnstone \& Bedard, 2004). The perception of a client's integrity also influenced auditors' estimates of: materiality (Bernardi \& Arnold, 1994; Arnold, Bernardi, \& Neidermeyer, 2001), the risk of a material misstatement (Kizirian, T. G., Mayhew, W., \& Sneathen L. D., Jr., 2005), and the probability of fraud (Anderson \& Marchant, 1989; Bernardi, 1997). Bernardi (1994) and Kizirian, T. G., Mayhew, W., \& Sneathen L. D., Jr. (2005) noted that client integrity also associated with the ability of an auditor to detect financial statement fraud. (Note 1)

This study investigates levels of trust among responses of 315 accounting students (69 from Afghanistan, 44 from Australia, 52 from Nepal, and 150 from the United States). While students would be most similar to first year auditors and consequently not involved in audit scope decisions, a concern should be that first-year auditors with higher level of trust would be less likely to identify potential client problems and bring them to the attention of their supervisors. The countries provide a contrast among the scores for Transparency International's (2008) Corruption Perceptions Index and Hofstede's (2001) cultural constructs of individualism and uncertainty avoidance; the sample also includes two countries that are not presently included in auditing-related research (i.e., Afghanistan and Nepal). (Note 2) Our analyses indicate that accounting students from both Australia and Nepal had significantly different levels of trust than the students from the United States (our control group). The students from Nepal (Australia) had a significantly lower (higher) level of trust than the students from the United States. Additionally, male students indicated a lower level of trust than female students. The remainder of this study follows a standard format: literature review, methodology, analysis and conclusions. 


\section{Literature Review}

\subsection{Trust: An Overview}

Webster's New Universal Unabridged Dictionary (1983, p. 554) defines trust as being the "assumed reliance on the character, strength, or truth of someone or something".

Therefore, trust in other individuals to act in one's best interests is basic to a functioning society; for example, the trust an individual must have for their doctor and hospital. For the patient, Hall (2006) maintains that this trust is very personal and is limited to a specific physician (person). Studies find a positive correlation between trust (i.e., expectations about the relationship, based in part on past experiences) and satisfaction (i.e., approval or disapproval of the physician's efforts). However, the type of personal trust established between a patient and physician is not possible throughout society; for example, investors cannot establish the same level of trust in the marketplace.

Yamagishi and Kakiuchi (2000) indicate that the act of trust involves assessing another person's trustworthiness; when a person trusts another person, he/she becomes vulnerable to the actions of the person trusted. Rousseau, Sitkin, Burt, and Camerer (1998, p. 395) maintain that trust is a "psychological state comprising the intention to accept vulnerability based upon positive expectations of the intention or behavior of another." Rosanas and Velilla (2003) suggest that personal trust develops when one of the individuals involved not only considers his/her personal interests but also takes a "genuine interest in the results for the other, this will create loyalty on the part of the other" (p. 57). Rempel, Holmes, and Zanna (1985) found that "the belief that one's partner will act in loving and caring ways whatever the future holds" (i.e., trust) was associated with the success of a close relationship for a sample of dating and married couples.

Dirks and Ferrin $(2002,614)$ note that trust has been associated with employees' belief in the level of "perceived fairness or justice in the organizational practices or decisions" of the leader. Dirks and Ferrin (613) suggest that, while high trust in a leader can lead to high job satisfaction, when one does not trust his/her leader, the intentions to consider quitting increase because:

[T] hey may be concerned about decision that the leaders might make (owing to perceptions of lack of integrity, fairness, honesty, or competence) and not want to put themselves at risk".

While Dirks and Ferrin studied trust in leadership, the notion of trust can also be applied to auditing in which the auditor must evaluate how much the client can be trusted. For example, Lee and Welker (2008) suggest that experienced auditors may develop skills to identify when a client is trying to deceive them. For example, Satava, Caldwell, and Richards (2006, pp. 279-281) suggest that requiring business ethics courses in undergraduate education, which are reinforced with continuing professional education in business ethics, are necessary to focus auditors on principles-based rather than rules-based ethics. Dirks and Ferrin's $(2002,621)$ meta-analysis findings include that trust in leadership associated work attitudes and job performance; in auditing terms, the level of professional skepticism and the scope of the audit.

\subsection{Trust and Auditors' Judgments}

Shaub (1996) also indicates that experience with the client and situational factors are important in determining the level of trust in the client; he suggests that an auditors' ability to calibrate the appropriate level of trust positively associates with the breadth of the auditor's exposure to a variety of experiences and training. For example, Rose (2007) found that less trusting auditors were more likely to be skeptical about perceived evidence of aggressive reporting. Goodwin (1999) found that auditors' sensitivity to client integrity (i.e., the trust an auditor has in their client) affected auditors' decision such as assessments of audit risk (Ponemon \& Gabhart, 1993; Beaulieu, 2001). (Note 3) While Krambia-Kapardis (2002) found that client integrity was significant with respect to perceptions of the relevance of the information, Kizirian Mayhew, and Sneathen (2005) found that auditors required more persuasive audit evidence (i.e., more external information) when management integrity was perceived as being low (i.e., auditors' did not trust the client).

Auditors' perceptions of client integrity affected the evaluations of engagement risk for a potential new client (Ayers \& Kaplan, 2003; Johnstone \& Bedard, 2004) as well as the decision to continue with an established client (Johnstone \& Bedard, 2004). Auditors' estimates of the level of materiality on an audit engagement were influenced by client integrity (Bernardi \& Arnold, 1994; Arnold et al., 2001). During the audit, perceptions of client integrity influenced auditors' estimations of the risk of material misstatement (Kizirian, T. G., Mayhew, W., \& Sneathen L. D., Jr., 2005), auditors' detection of fraud (Bernardi, 1994; Kizirian, T. G., Mayhew, W., \& Sneathen L. D., Jr., 2005) as well as estimates of the probability of fraud (Anderson \& Marchant, 1989; Bernardi, 1997). Mautz and Sharaf (1961, p. 29) suggest that auditors who note indications that a client's management is "questionable, he is likely to apply more 
rigorous procedures." Munter and Ratcliffe (1998), Albrecht and Willingham (1993), and Loebbecke, Eining, and Willingham (1989) provide lists of attitudes and ethical values that are indicative of management's integrity, which could lead to management fraud:

(1) Management operating and financing decisions are dominated by a single person.

(2) Management's attitude towards financial reporting is unduly aggressive.

(3) Management places undue emphasis on meeting earnings projections.

(4) Management's reputation in the business community is poor.

Knapp and Knapp (2001) found that audit managers were more effective in assessing the risk fraud using analytical procedures than audit seniors; similarly, Bernardi found that audit managers were more effective at detecting fraud than audit seniors. For the Bernardi study, the detection rate for managers was increased when the managers reviewed their firms' estimates of client integrity (i.e., ability to trust the client's statements). Pincus (1990) and Bernardi (1994) found that auditors' prior beliefs about the existence of fraud were a significant factor in the detection of fraud. Finally, Kerler and Killough (2009) found that the level of an auditors' trust in the client increased (decreased) as an auditor became more (less) satisfied with the actions of the client. As the level of trust decreased for the auditors who were less satisfied with their clients, the level of the auditors' fraud-risk assessments increased. However, there was not an association between the increased levels of trust and fraud-risk assessments for auditors who were satisfied with their clients.

\subsection{Gender Differences in Ethics/Trust}

Rempel et al. (1985) found that, while women tended to be more trusting across a series of components of trust, men tended to discriminate among these components. The literature on the Defining Issues Test and corporate decision-making suggests that women are more sensitive to the ethical cues that exist in an environment. Bernardi and Arnold (1997) found that female audit managers scored 12 points higher on the Defining Issues Test (i.e., a measure of ethical sensitivity) (Rest, 1979) than male managers and male and female audit seniors. Bernardi (1994) found that managers who scored higher on the Defining Issues Test (i.e., were more ethically sensitive) were more likely to detect fraud. Bernardi and Arnold (1994) noted that the level of materiality (i.e., how small an error would have to be) varied inversely with the managers' level of ethical sensitivity (as measured on the Defining Issues Test) on which female managers scored significantly higher.

Research also indicates that corruption is lower in countries in which women are more involved in public life (Swamy, Knack, Lee, \& Azfar, 2001). For example, international research indicates that women are less likely to take bribes and condone taking bribes (Buchan, Johnson, \& Croson, 2008). Golesorkhi (2006) found that North American women rated integrity significantly higher in their decision process than women from Europe and both women and men from Southeast Asia. Roxas and Stoneback (2004) found that female students were significantly more ethical than male students in a sample that included students from eight countries: Australia, Canada, China, Germany, the Philippines, Thailand, the Ukraine and the United States. However, there have been varying results regarding trust and gender, with some research indicating that women have slightly higher levels of trust (Feingold, 1994) to those that show that they have less trust because of their experience of discrimination in organizations (Alesina \& LaFerrara, 2002). Given this, women's inherent level of trust may be less than men's level of trust, our first research hypothesis (all hypotheses stated in their alternate form) is:

H1: An accounting student's propensity to trust others will vary by gender.

\subsection{Culture and Corruption}

Hofstede (2001, p. 112) maintains that individuals within a society have similar perceptions, which represent a:

[S]et of likely reactions of citizens with a common mental programming. . . reactions need not be found within the same persons, but only statistically more often in the same society.

Of Hofstede's (2001) four cultural constructs, individualism and uncertainty avoidance are the constructs that are frequently associated with ethics research. Ethical behaviors "reflect the values and beliefs of [individuals'] culture" (Buller, Kohis, \& Anderson, 1991, p. 768). Research findings indicate auditors from countries with higher uncertainty avoidance scores used lower materiality levels in their work (Arnold et al., 2001); Arnold, Bernardi, and Neidermeyer (1999) also found that the decision to do additional audit work associated positively with Hofstede's individualism construct. In a replication study of Hofstede's (1980) original work on culture, Smith (2002) found that the individualism construct derived from the responses of 1,000 staff members working for international accounting firms had a .75 correlation with Hofstede's (2001) data for individualism. Hofstede (2001) indicates that 
uncertainty avoidance (p. 160) and individualism (p. 239) are related to trust:

Low Uncertainty Avoidance: Most people can be trusted.

High Uncertainty Avoidance: One can’t be careful enough with other people, not even with family.

A consequence of particularist thinking is that in a collectivist society a relationship of trust should be established between two parties before they can do business.

One of the implications of the differences among cultures with respect to trust that Hofstede suggests is that workers should be made aware of the care an organization will provide - especially in a multicultural work force (Golesorkhi, 2006).

In an auditing context, Arnold et al. (2001) found that the level of an auditor's estimate of materiality varied with client integrity and uncertainty avoidance. Auditors examining a low-integrity client's statements assigned a lower level of materiality (i.e., demonstrating a lower level of trust) to the audit than did auditors examining a high-integrity client's financial statements. Additionally, auditors from high uncertainty avoidance countries assigned a lower level of materiality than did auditors from lower uncertainty avoidance countries. Arnold et al. (1999) found that the probability of doing more audit work decreased as the level of individualism increased (i.e., the auditor placed more emphasis on personal relationships - collectivism), which suggests our second hypothesis.

H2: An accounting student's propensity to trust others will vary by country.

\section{Methodology}

\subsection{Sample}

Our sample includes the responses of 315 accounting students (69 from Afghanistan, 44 from Australia, 52 from Nepal, and 150 from the United States). The data employed a trust questionnaire (Wrightsman, 1991) and a short demographic questionnaire; all of the data were gathered in early 2009. The data in Table 1 indicate that the four samples are approximately equivalent with respect to the male/female sample proportions: 44.9/55.1 percent for Afghanistan, 50.0/50.0 percent for Australia, 51.9/48.1 percent for Nepal and 48.0/52.0 percent for the United States.

Table 1. Gender Breakout by Country

\begin{tabular}{cccccc}
\hline & Afghanistan & Australia & Nepal & USA & Total/Avg. \\
\hline Men & 31 & 22 & 27 & 72 & 152 \\
$\mathrm{n}$ & 44.9 & 50.0 & 51.9 & 48.0 & 48.3 \\
$\%$ & & & & & \\
Women & 38 & 22 & 25 & 78 & 163 \\
$\mathrm{n}$ & 55.1 & 50.0 & 48.1 & 52.0 & 51. \\
$\%$ & 69 & 44 & 52 & 150 & 315 \\
Total & 21.9 & 14.0 & 16.5 & 47.6 & 100.0 \\
$\mathrm{n}$ & & & & & \\
\hline
\end{tabular}

The countries were selected from among those where the authors had contacts and/or acquaintances and thus were able to gather data there. The criteria used to select countries included that they provide a contrast among the scores for Transparency International's Corruption Perceptions Index (2008) and Hofstede's (1980) cultural constructs of individualism and uncertainty avoidance (Figure 1). (Note 4) Of Hofstede's cultural constructs of individualism and uncertainty avoidance, individualism provides the largest differentiation between the two sets of countries (Nepal and Afghanistan versus the United States and Australia) - 14 and 20 versus 89 and 91 (a space of 70 points). For uncertainty avoidance the space is only 10 points -- 46 and 51 versus 60 and 70 . On a scale of 1 to 10 for the Corruption Perceptions Index, the space is 4.8 points -1.3 and 2.7 versus 7.5 and 8.5 . (Note 5) 
Panel A: Individualism (Hofstede, 2001, p. 215)

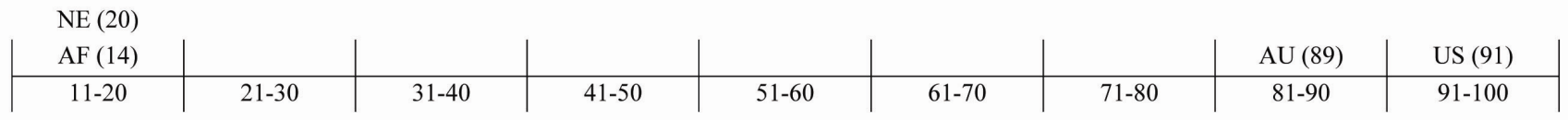

Panel B: Uncertainty Avoidance (Hofstede, 2001, p. 151)

\begin{tabular}{|c|c|c|c|c|c|c|c|} 
& & & NE (60) & AS (70) & \\
\hline $11-20$ & $21-30$ & $31-40$ & $41-50$ & $51-60$ & $61-70$ & $71-80 \quad$
\end{tabular}

Panel C: Corruption Perceptions Index (Transparency International, 2008)

\begin{tabular}{|c|c|c|c|c|c|c|c|c|}
\hline \multirow{2}{*}{\multicolumn{2}{|c|}{\begin{tabular}{|l}
$\mathrm{AU}(1.3)$ \\
$1.1-2.0$
\end{tabular}}} & US (2.7) & & & & & NE (7.3) & AF (8.5) \\
\hline & & $2.1-3.0$ & $3.1-4.0$ & $4.1-5.0$ & $5.1-6.0$ & $6.1-7.0$ & $7.1-8.0$ & $8.1-9.0$ \\
\hline \multicolumn{9}{|c|}{ Values in parentheses (brackets) are the country's corruption index (cultural construct values) } \\
\hline $\mathrm{AF}$ & \multicolumn{3}{|c|}{ Afghanistan } & & $\mathrm{NE}$ & \multicolumn{3}{|l|}{ Nepal } \\
\hline $\mathrm{AU}$ & \multicolumn{3}{|c|}{ Australia } & & US & \multicolumn{3}{|l|}{ United States } \\
\hline
\end{tabular}

Figure 1. Transparency International's Corruption Index

\subsection{Research Questionnaire}

Our research instrument consisted of a short background data questionnaire and the 14 Trustworthiness items of Wrightsman's (1991) Philosophies of Human Nature questionnaire. The instrument was purposely kept short so that the probability of students randomly responding to the questionnaire was minimized. The background questionnaire asked the participants to provide their home country, gender and major. The question on home country provided a means to ensure that only students from our four countries were included in the sample - exchange students from other countries were eliminated from the sample to avoid cultural biases.

Because English is not the spoken native language in Afghanistan, one exchange student from Afghanistan translated the survey into the country's language; then, the survey was back-translated by a second student from Afghanistan. (Note 6) Student translators were used as their version of the language's intricacies would be more current for our sample of students. The surveys were given to a contact person (i.e., a professor teaching at a university in the country). The contact person was asked to distribute our survey to business students at the beginning of the semester.

For our dependent variable in this research (Trustworthiness), we used a six-point Likert scale shown above. To avoid confusion in the survey instrument, we used a one-to-six scale and then converted it to Wrightsman's scale of minus three through plus three after the participants took the survey. We reverse coded every other response on the Trustworthiness scale of Wrightsman's (1991) Philosophies of Human Nature questionnaire. We used the order that Wrightsman (1991) used in his overall survey; consequently, the positively worded questions were coded on a scale from 'Disagree Strongly' (-3) to 'Agree Strongly'. For the negatively worded questions (i.e., questions highlighted in Appendix A - highlighting not used on actual surveys) were coded on a scale was reversed in the data-entry process. Scores on the Trustworthiness scale could range from a -42 ( 3 X 14 items) to a +42 . Cronbach's alpha for the original standardization study on trustworthiness was .78; for our study, Cronbach's alpha was .73.

\subsection{Research Variables}

Our two variables were gender and country, which are both dichotomous variables. We coded our gender variable as one for male students and zero for female students. We coded country in a series of indicator variables using the sample from the United States as zero for each country variable (i.e., our control group); consequently, we used three country variables: Afghanistan, Australia and Nepal. We used the United States as our control group because most prior ethics research has focused on U.S. samples. Each of the three country variables was coded as one if the student 
came from that country; otherwise, the variable was coded as zero. We also controlled for an individual's level in college (i.e., freshman [0], sophomores [1], juniors [3] and seniors [4]).

We also controlled for social desirability response bias using Paulhus' (1991) Impression Management Subscale that asks participants to respond to 20 statements on a seven-point Likert scale. The Impression Management Subscale (IMS) reverse codes every other response; for example, the first two questions on the IMS are "Sometimes I tell lies if I have to" and "I never cover up my mistakes". On the first statement, responding in a socially desirable manner is on the strongly disagree side of the Likert scale - telling a lie is not a socially desirable behavior. Similarly, on the second statement, responding in a socially desirable manner is on the strongly agree side of the Likert scale covering up one's mistakes is not a socially desirable behavior. Consequently, scores on the Impression Management Subscale (IMS) could range from 0 to 20. Cronbach's alpha for the IMS ranges from .75 to .86 (Paulhus, 1988); the IMS has a Cronbach's alpha of .80 in this study.

\section{Data Analysis}

The actual range of trustworthiness scores for the 315 students in our study was a -25 to a +28 (Table 2). While the upper point on the range of scores are quite similar for the students from Afghanistan (+17), Australia $(+26)$ and the United States $(+28)$, the upper point on the range of scores is not as expansive on the positive side of the scale for the sample of students from Nepal (i.e., only a +3 ). Our range of scores for social desirability response bias for the 315 students in our study was a 0 to a 16 (Table 2). While the range of the data are quite similar for the students from Afghanistan, Nepal and the United States (i.e., between 0 and 16), the range is not as expansive for the sample of students from Australia (i.e., between 0 and 9). The only difference between male and female students' average responses was for social desirability response bias for the students from the United States; female students' scored higher on Paulhus' Impression Management subscale $(\mathrm{p}=0.026)$.

Table 2. Test Scores by Country

\begin{tabular}{lccccc}
\hline & Afghanistan & Australia & Nepal & USA & Total/Avg. \\
\hline Trust Score & -0.6 & 2.2 & -12.3 & -3.1 & -3.4 \\
Men & 0.7 & 3.5 & -7.9 & 1.1 & 0.0 \\
Women & 0.1 & 2.9 & -10.2 & -0.9 & -1.7 \\
Total & -22 to +17 & -23 to +26 & -25 to +3 & -24 to +28 & -25 to +28 \\
Range & & & & \\
SDRB Score & 5.9 & 5.7 & 5.6 & 5.3 & 5.5 \\
Men & 5.2 & 4.9 & 5.6 & 6.5 & 5.8 \\
Women & 5.5 & 5.3 & 5.6 & 5.9 & 5.7 \\
Average & 1 to 13 & 0 to 9 & 0 to 12 & 0 to 16 & 0 to16 \\
Range & Social Desirability Response Bias (Paulhus, 1991) & & \\
\hline SDRB & Level of individual trust (Wrightsman, 1991) & & \\
Trustworthiness & &
\end{tabular}

Our two individual difference variables dealt with whether or not an individual's propensity to trust others varied by: gender (H1) and country (H2); our regression model (Table 3) provides support for both of these hypotheses. The students from both Australia and Nepal had significantly different levels of trust (as measured on Wrightsman's Trustworthiness scale, 1991). Male students indicated a lower level of trust than female students

$(\mathrm{p}=0.002)$. While the students from Nepal had a significantly lower level of trust than the students from the United States $(\mathrm{p}<0.000)$, the students from Australia had a significantly higher level of trust than the students from the United States $(\mathrm{p}=0.022)$. There was not a significant difference in the level of trust between the students from Afghanistan and the students from the United States. Finally, an individual's level of trust did not vary with their propensity to respond in a socially desirable manner (i.e., our control variable). 
Table 3. Regression Model for Trustworthiness

\begin{tabular}{|c|c|c|c|c|}
\hline Adjusted $\mathrm{R}^{2}$ & F Stat & Prob F & & \\
\hline .183 & 24.45 & $<0.000$ & & \\
\hline Term & Coefficient & $\underline{\text { T Stat }}$ & $\underline{\text { Prob T }}$ & $\underline{\text { Part Adj } R^{2}}$ \\
\hline NEPAL & -4.81 & -7.00 & $<0.000$ & .149 \\
\hline GENDER & -1.58 & -3.16 & 0.002 & .023 \\
\hline AUSTRALIA & 1.69 & 2.30 & 0.022 & .011 \\
\hline COUNTRY & \multicolumn{4}{|c|}{$\begin{array}{l}\text { Indicator variable coded as } 1 \text { (0) for students from Nepal (the United } \\
\text { States) }\end{array}$} \\
\hline GENDER & \multicolumn{4}{|c|}{ Indicator variable coded as $1(0)$ for male (female) students } \\
\hline
\end{tabular}

\section{Conclusions}

Our study examined the propensity of individuals from Afghanistan, Australia, Nepal and the United States to trust the actions of others. Prior research has predominantly focused on the United States in determining trust and the role it plays in an individual's decision-making process. The contribution of this research to the current literature in three areas: differences among countries in the level of trust and gender differences in trust; both of these findings have implications for the auditing profession. Our findings show that an individual's level of trust varied between the students from the United States and the students from Nepal and Australia; however, there was not a difference between level of trust varied between the students from the United States and the students from Afghanistan. Our analysis also includes a finding that an individual's trust level associates with the participant's gender.

While we took the precaution to control for socially desirable responding by using Paulhus' (1991) instrument, it was not a significant factor in our analysis. It may be that the ranges of the scores for each country were so similar that social desirability response bias was not a factor; another possible explanation is that the indicator variables for three of the four countries (i.e., the U.S. was our control country and thus coded as zero for the other three indicator variables) absorbed the influence of this factor.

Our findings also indicate that an individual's gender (H1) was a factor in the level of trust; women were more trusting than men in our sample. The implication here for the practice of auditing suggests a mix in the gender composition of the audit team. The increased level of trust found in women might be offset by their increased sensitivity to the ethical implications of cues within the audit environment (Bernardi \& Arnold, 1994).

Our finding of differences among countries (H2) in the level of individual trust has implications in the field of international auditing. While the countries of the world are working at harmonizing their accounting and auditing standards, differences in the amount of work actually done on an audit could be determined by the level of trust in a client. For example, our findings suggest that auditors from Nepal would probably do more audit work than auditors from Afghanistan, Australia, and the United States. Similarly, our findings suggest that auditors from Australia would probably do less audit work than auditors from Afghanistan, Nepal and the United States, which suggest that practitioners be more skeptical of the results of Australian audits. It may be that the level of freedom in these countries could influence the level of trust. For example, in a country dominated by another country such as Nepal, the level of concern over freedom may make individuals less trusting. Conversely, in a free society such as Australia, the level of trust should be significantly higher.

Our research has three limitations. First, the sample comes from university students who may not represent the entire population from their countries. Second, we used students as surrogates for newly-hired auditors' attitudes; a justification for this procedure is that research indicates that attitudes concerning dishonesty are carried forward into the workplace from college (Lawson, 2004; Sims, 1993). Third, while prior research examined samples from the United States and this research added individuals from Afghanistan, Australia, and Nepal, the findings of this research may still not be generalizable to other populations.

Future research should include samples from other countries whose cultural constructs provide contrasts with those of the countries we sampled. For example, with respect to individualism, the countries we sampled fell at either end of the spectrum (Figure 1: Panel A) for individualism; future studies could sample from countries closer to the 
middle of the spectrum being careful to provide an adequate separation to ensure contrast. The same situation exists for the corruption perceptions index where our countries fell at either end of this spectrum. The opposite was true for uncertainty avoidance where our sample came from the center of this spectrum (Figure 1: Panel B); here, future research might select countries at either end of this spectrum.

\section{References}

Albrecht, W. S., \& Willingham, J. J. (1993). An evaluation of SAS No. 53, The auditor's responsibility to detect and report errors and irregularities. 102-124, in The Expectation Gap Standards, American Institute of Certified Public Accountants: New York, NY.

Alesina, A. \& La Ferrara, E. (2002). Who trusts others? Journal of Public Economic, 85 (2), 207-234. http://dx.doi.org/10.1016/S0047-2727(01)00084-6

Anderson, U. \& Marchant, G. (1989). Auditor's assessment of the competence and integrity of auditee personnel, Auditing: A Journal of Practice \& Theory, 8 (Supp), 1-16.

Arnold, D. F., Bernardi, R. A., \& Neidermeyer, P. E. (1999). The effect of independence on decisions concerning additional audit work: A European perspective, Auditing: A Journal of Practice \& Theory, 18 (Supplement), 2, 45-67.

Arnold, D. F., Sr., Bernardi, R. A. \& Neidermeyer, P. E. (2001). The associations between European materiality estimates and client integrity, national culture and litigation, International Journal of Accounting, 36 (4), 45-67.

Ayers, S. and Kaplan, S. (2003). Review partners' reactions to contact partner risk judgments of prospective clients, Auditing: A Journal of Practice \& Theory, 21 (1), 29-45.

Beaulieu, P. R. (2001). The effects of judgments of new clients' integrity upon risk judgments, audit evidence, and fees, Auditing: A Journal of Practice \& Theory, 20 (2), 85-99.

Bernardi, R. A. \& Arnold, D. F. (1997). Examination of Moral Development within Public Accounting by Gender, Staff Level, and Firms, Contemporary Accounting Research, 14 (4), 653-668. http://dx.doi.org/10.1111/j.1911-3846.1997.tb00545.x

Bernardi, R. A. \& D. F. Arnold, Sr. (1994). The influence of client integrity and competence and auditor characteristics on materiality estimates, Irish Accounting Review, 1 (1), 1-23.

Bernardi, R. A. (1994). Fraud detection: The effect of client integrity and competence and auditor cognitive style, Auditing: A Journal of Practice \& Theory, 13 (Supplement), 68-84.

Bernardi, R. A. (1997). Probability of fraud estimates: The impact of client integrity and competence, Research on Accounting Ethics, 3 (1), 119-140.

Buchan, N., Johnson, E. \& Croson, R. (2006). Let's get personal: An international examination of the influence of communication, culture, and social distance on other regarding preferences, Journal of Economic Behavior and Organization, 60 (3), 373-398. http://dx.doi.org/10.1016/j.jebo.2004.03.017

Buller, F. P., Kohis, J. J. \& Anderson, K. S. (1991). The challenge of global ethics, Journal of Business Ethics 10 (10), 767-775. http://dx.doi.org/10.1007/BF00705711

Dasgupta, S. (1988). Truth as a commodity, In D. Gambetta (Ed.), Trust: Making or breaking cooperative relations, (pp. 49-72). New York, NY: Basil Blackwell.

Dirks \& Ferrin, (2002). Trust in leadership: a meta-analytic findings and implications for research and practice, Journal of Applied Psychology, 87 (4), 611-628. http://dx.doi.org/10.1037/0021-9010.87.4.611

Feingold, A. (1994). Gender differences in personality: a meta-analysis, Psychological Bulletin, 116 (3), 429-456. http://dx.doi.org/10.1037/0033-2909.116.3.429

Golesorkhi, B. (2006). Gender differences and similarities in judgments of trust, Women in Management Review, 21 (2), 195-210. http://dx.doi.org/10.1108/09649420610657380

Goodwin, J. (1999). The effects of source integrity and consistency of evidence on auditors' judgments, Auditing: A Journal of Practice \& Theory, 18 (2), 1-16.

Hall, M. A. (2006). Researching Medical Trust in the United States, Journal of Health Organization and Management, 20 (5), 456-467. http://dx.doi.org/10.1108/14777260610701812

Hofstede, G. (1980). Culture's Consequences, $1^{\text {st }}$ Edition, Sage Publications: Beverly Hills, CA. 
Hofstede, G. (1984). Cultural Dimensions in management and Planning. Asia Pacific Journal of Management, 1 (2), 81-99. http://dx.doi.org/10.1007/BF01733682

Hofstede, G. (2001). Culture's Consequences, $2^{\text {nd }}$ Edition, Sage Publications: Beverly Hills, CA.

Husted, B. W. (1999). Wealth, culture, and corruption, Journal of International Business Studies, 30 (2), 339-360. http://dx.doi.org/10.1057/palgrave.jibs.8490073

Johnstone, K. M. \& Bedard, J. C. (2004). Audit firm portfolio management decisions, Journal of Accounting Research, 42 (4), 659-690. http://dx.doi.org/10.1111/j.1475-679X.2004.00153.x

Kerler, W. A. \& Killough, L. N. (2009). The effects of satisfaction with a client's management during a prior audit engagement, trust, and moral reasoning on auditors' perceived risk of management fraud, Journal of Business Ethics, 85 (2), 109-136. http://dx.doi.org/10.1007/s10551-008-9752-x

Kizirian, T. G., Mayhew, W., \& Sneathen L. D., Jr. ( 2005). The impact of management integrity on audit planning and evidence. Auditing: A Journal of Practice \& Theory, 24 (2), $49-67$.

Knapp, C. \& Knapp, M. (2001). The effects of experience and explicit fraud risk assessment in detecting fraud with analytical procedures, Accounting, Organizations, and Society, 26 (1), 25-37. http://dx.doi.org/10.1016/S0361-3682(00)00005-2

Krambia-Kapardis, M. (2002). A fraud detection model: A must for auditors. Journal of Financial Regulation and Compliance, 10 (3), 266-278. http://dx.doi.org/10.1108/13581980210810256

Lawson, R. A. (2004). Is classroom Cheating related to business students' propensity to cheat in the 'real world'? Journal of Business Ethics, 49 (2), 189-199. http://dx.doi.org/10.1023/B:BUSI.0000015784.34148.cb

Lee, C. C. \& Welker, R. B. (2008). Identification of Perceived Interviewee Behaviors that Influence Auditors' Assessment of Deception, International Journal of Auditing, 12 (3), 205-220. http://dx.doi.org/10.1111/j.1099-1123.2008.00380.x

Loebbecke, J. K., Eining, M. M., \& Willingham, J. J. (1989). auditors' experience with material irregularities: Frequency, nature and delectability. Auditing: A Journal of Practice \& Theory, 9 (1), 1-28.

Mautz, R. K. and H. A. Sharaf. 1961. The Philosophy of Auditing, American Accounting Association: Evanston, IL.

Mishra, A. K. (1996). Organizational responses to crisis: The centrality of trust, in Kramer, R. M. and Tyler, T. R. (Eds.), Trust in Organizations: Frontiers of theory and research, 261-287, London: Sage.

Munter, P., \& Ratcliffe, T. A. (1998). Auditor's responsibilities for detection of fraud. National Public Accountant $43(6), 37-43$.

Paulhus, D. L. (1991). Balanced Inventory of Desirable Responding (BIDR), In J. P. Robinson, P. R. Shaver, and L. S. Wrightsman (Eds.), Measures of Personality and Psychological Attitudes, Vol. 1, Measures of social psychological attitudes, (pp. 37-41). New York, NY: Academic Press.

Paulhus, D. L. (1988). 'Development of the Balanced Inventory of Desirable Responding', Unpublished Manuscript, University of British Columbia.

Pincus, K. V. (1990). Auditor individual differences and fairness of presentation judgments, Auditing: A Journal of Practice \& Theory, 9 (3), 150-166.

Ponemon, L.A. \& Gabhart, D. L. (1993). Ethical reasoning in accounting and auditing, Research Monograph Number 21, CGA-Canada Research Foundation, Vancouver, BC.

Rempel, J., Holmes, J. \& Zanna, M. (1985). Trust in close relationships, Journal of Personality and Social Psychology, 49 (1), 95-112. http://dx.doi.org/10.1037/0022-3514.49.1.95

Rest, J. R. (1979). Development in Judging Moral Issues, Center for the Study of Ethical Development, University of Minnesota, Minneapolis, MN: University of Minnesota Press.

Rosanas, J. \& Velilla, M. (2003). Loyalty and trust as the ethical bases of organizations, Journal of Business Ethics, 44 (1), 49-59. http://dx.doi.org/10.1023/A:1023238525433

Rose, J. M. (2007). Attention to evidence of aggressive financial reporting and intentional misstatement judgments: Effects of experience and trust, Behavioral Research in Accounting, 19 (1), 215-229. http://dx.doi.org/10.2308/bria.2007.19.1.215 
Rousseau, D. M., Sitkin, S. B., Burt, R. S., \& Camerer, C. (1998). Not so different after all: A cross-discipline view of trust. Academy of Management Review, 23 (3), 393-404. http://dx.doi.org/10.5465/AMR.1998.926617

Roxas, M. L. \& Stoneback, J. Y. (2004). The importance of gender across cultures in ethical decision-making, Journal of Business Ethics, 50 (2), 149-165. http://dx.doi.org/10.1023/B:BUSI.0000022127.51047.ef

Satava, D., Caldwell, C., \& Richards, L. (2006). Ethics and the auditing culture: Rethinking the foundation of accounting and auditing, Journal of Business Ethics, 64 (3), 271-284. http://dx.doi.org/10.1007/s10551-005-0556-y

Shaub, M. (1996). Trust and suspicion: The effects of situational and dispositional factors on auditors' trust of clients, Behavioral Research in Accounting, 8 (1), 154-174.

Sims, R. (1993). The relationship between academic dishonesty and unethical business practices, Journal of Education for Business, 68 (4), 207-211. http://dx.doi.org/10.1080/08832323.1993.10117614

Smith, A. (2002). Testing the stability of the global concept of culture in an accounting context, Accounting Enquiries, 11 (2), 227-248.

Swamy, A., Knack, S, Lee, Y, \& Azfar, O. (2001). Gender and corruption, Journal of Development Economics, 64 (1): 25-55. http://dx.doi.org/10.1016/S0304-3878(00)00123-1

Transparency International; (2008). Corruption Perceptions Index, [Online] Available: http://www.transparency.org/ news_room/in_focus/2008/cpi2008/cpi_2008_table.

Webster's New Universal Unabridged Dictionary. (1995), New York: Simon Schuster.

Wrightsman, L. S. (1991). Interpersonal trust and attitudes toward human nature, In J. P. Robinson, P. R. Shaver, and L. S. Wrightsman (Eds.), Measures of personality and social psychological attitudes: Vol. 1: Measures of social psychological attitudes. San Diego, CA: Academic Press.

Yamagishi, T. \& Kakiuchi, R. (2000). It takes venturing into the tiger's cave to steal a baby tiger: Experiments on the development of trust relationships, in J. Raub and W. Weesie (Eds.), The Management of Durable Relations. Amsterdam, Netherlands: Thelma Thesis Publishers.

\section{Notes}

Note 1. Materiality is an auditing term referring the amount of an error that would affect an investor's decision about a stock.

Note 2. Two of Hofstede's (1980) dimensions relating to national culture are individualism and uncertainty avoidance, which Hofstede (1984, 83-84) describes as:

Individualism versus Collectivism: Individualism stands for a preference for a loosely knit social framework in society. The fundamental issue addressed by this dimension is the degree of interdependence a society maintains among individuals.

Strong versus Weak Uncertainty Avoidance: The degree to which the members of a society feel uncomfortable with uncertainty and ambiguity. Strong Uncertainty Avoidance societies (for example) maintain rigid codes of belief and behavior and are intolerant towards deviant persons and ideas.

Note 3. Components of the association between integrity and trust include credibility (Mishra, 1996) and telling the truth (Dasgupta, 1988).

Note 4. Hofstede does not currently provide constructs for Afghanistan and Nepal; consequently, for the purposes of this research we used the values for Pakistan (Afghanistan) and China (Nepal).

Note 5.In Transparency International's Corruption Perceptions Index (2008), the country least likely to bribe is rated as a 10.0 and the most likely is rated a 1.9 , which is the opposite of what one would expect. To make the scores follow intuition, we subtracted Transparency International's scores from ten (i.e., higher scores now represent the more corrupt countries).

Note 6. The students from Nepal were enrolled in English-speaking universities; consequently, their survey instrument did not have to be translated. 